\title{
Detection of Novel Coronavirus (nCov-2019) using Lung CT Scan by Marker-based Watershed Segmentation method

\author{
Dr. V.Ajantha Devi
} \\ AP3 Solution, Research Head, Chennai, Tamil Nadu, India \\ Email: ap3solutionsresearch@gmail.com ${ }^{1}$
}

\begin{abstract}
This research study is expected to set up an early screening model to detect Novel Coronavirus (2019 - nCov) Pneumonia, with aspiratory CT scan utilizing Digital Image Processing procedures. The signs of registered tomography (CT) imaging of 2019 - nCov had their attributes, which are not the same as different sorts of viral Pneumonia. Accordingly, clinical specialists require another early analytic criterion for this new kind of Pneumonia at the earliest opportunity. The applicant contamination locales were handled under Digital Image Processing systems: image preprocessing, image enhancement and image segmentation of a 3-dimensional pneumonic CT image set capturing. These isolated images were then sorted into 2019 - nCov, using a marker-based watershed segmentation method
\end{abstract}

Keywords : Lung CT Scan, nCov-2019, Watershed Segmentation

\section{INTRODUCTION}

Toward the finish of 2019, the Novel Coronavirus sickness (2019 - nCov) Pneumonia happened in China. On January 24, 2020, [1-11, 18] abridged the clinical characteristics of 41 patients with 2019 - nCov, showing that the typical beginning side effects were fever, hack, myalgia, or exhaustion. All these 41 patients had Pneumonia and their chest CT assessment demonstrated irregularities. The difficulties included intense respiratory misery disorder, extreme heart injury, and auxiliary contaminations.

Thirteen (32\%) patients were admitted to the emergency unit, and six (15\%) passed on. The Kok-KH6 group at the University of Hong Kong found the presence of 2019 nCov for the first run through.
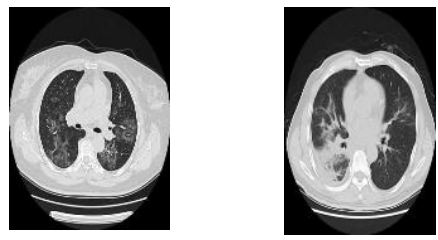

(a) $2019-$ $\mathrm{nCov}$

(b) Influenza-A viral pneumonia

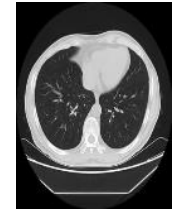

(c) Nil pneumonia manifestations
Figure 1.1. Typical transverse-section CT images

A great extent of the anomalous chest CT scan were acquired from patients with this malady. The signs of CT imaging of 2019 - nCov cases had their own attributes, not quite the same as the indications of CT imaging of other viral Pneumonia, for example, Influenza-A viral pneumonia, as appeared in Figure 1.1 In this manner, clinical specialists called for supplanting nucleic corrosive testing with lung CT [12-17, 19] scan as one of the early indicative criteria for this new sort of Pneumonia at the earliest opportunity.

The quick advancement of digital image processing techniques has been widely applied in the clinical field, including organ segmentation and image enhancement and repair, supporting the subsequent medical diagnosis. In this study, marker-based Segmentation was used to segment CT image datasets and extract the region of infection of 2019 nCov. The findings might greatly assist in the early screening of patients with 2019 - nCov.

\section{Proposed methodology}

The study included 618 CT samples (2019- nCov), [111, 18] 224 Influenza-A-viral-pneumonia, and 175 healthy case). Subsequently, a total of 3957 candidate cubes were generated from the 3D segmentation model. Only the territory close to the middle of this cube contained maximum information about this focus of infection. 


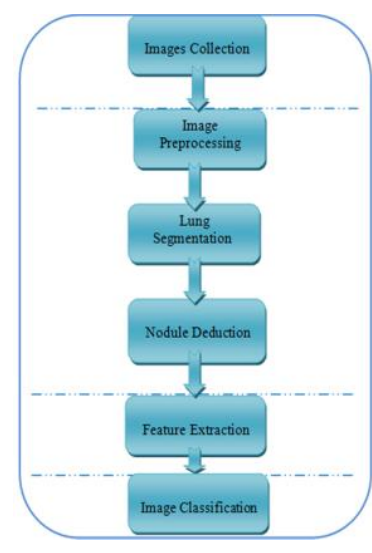

Figure 2.1 Flow Diagram of the proposed methodology

Hence, only the center image together with the two neighbors of each cube was collected to represent this region for future classification steps. Next, two professional radiologists manually classified all image patches into two types: irrelevant-to-infection and Pneumonia. The latter category's images were recognized automatically as 2019nCov or Influenza-A-viral-pneumonia based on the clinical diagnosis results.

\section{A. Acquisitions of CT scan}

CT images were gathered utilizing multi-finder CT. All patients $[1-11,18]$ were checked in the recumbent situation with their breath held toward the finish of motivation. The field of view was set from the zenith to the base of the lungs. The cylinder voltage and the current were $120 \mathrm{kV}$ and 30-140 mA, individually. All information was recreated utilizing a standard remaking piece. The reproduction lattice was $512 \times 512$, and the cut thickness of recreated segments was between $0.625 \mathrm{~mm}$ what's more, 1 $\mathrm{mm}$. images were seen at window settings advanced for the appraisal of the lung parenchyma (width $1500 \mathrm{HU}$; level $500 \mathrm{HU})$.

\section{B. Image Enhancement}

It is one of the essential strategies utilized by specific systems to enhance an image. This stage is used to get the subtleties that need and spotlight certain image territories, such as changing brilliance and difference, tuning an image, and so forth. Such image enhancement improvement methods are accordingly used to identify nCov growth in advance.

There are three kinds of procedures right now, as Gabor Filter, auto improvement strategy and Fourier Filter Vol. 4 (5), November 2020, www.ijirase.com techniques. The point of enhancing the image is to modernize the understanding of data remembered for the images for typical sight or discover better contribution for different kinds of electronic image handling strategies. Image enhancing strategies can be characterized into two classes: Spatial area techniques and recurrence space techniques [14].

1) Spatial space strategies which work legitimately on pixels.

2) Frequency space strategies that work on the Fourier Filter of an image.

The different CT scan enhancing procedures can be portrayed as recurrence space techniques and spatial space strategies. These connect smoothing of CT scan image and diminishing of clamors, obscuring and so on. In spite of the fact that there are numerous potential ways to improve the image Gabor Filter as shown in Figure 2.3 was seen as able for the CT image. In the enhancement of the Image step, the accompanying strategy used called as Gabor Filter.

Gabor Filter: A Gabor Filter is a straight Filter whose replication interpretation is characterized by a symphonious capacity duplicated by a Gaussian capacity. Because of the quality-compression property, the Fourier Filter of the Gabor Filters is the drive transcript of the Fourier Filter of the consonant capacity and the Fourier Filter as shown in the Figure 2.4 of the Gaussian function.

It generally investigations whether the solid headings of the purpose of examination or the neighborhood the investigation zone have any solid recurrence content. A lot
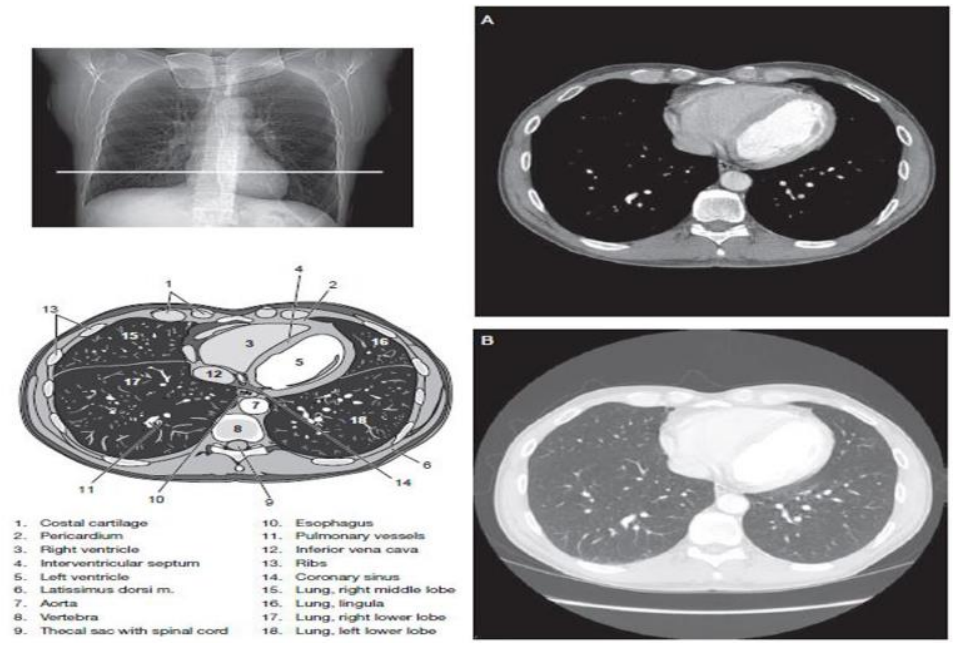

of Gabor Filters with various frequencies and arrangements can be useful to vivify valuable highlights from an image. 

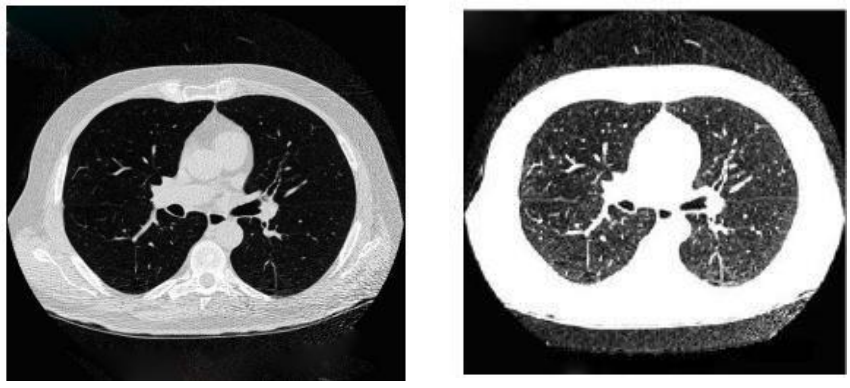

(a) Original image

(b) enhanced image
Figure 2.3. Enhanced image after applying Gabor filter (a) Original image

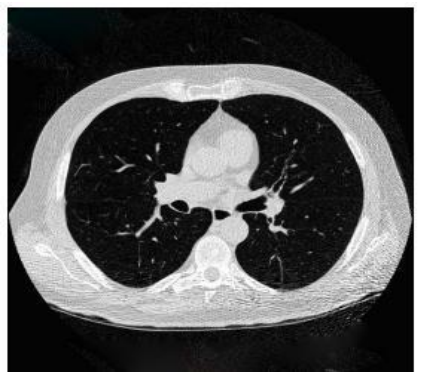

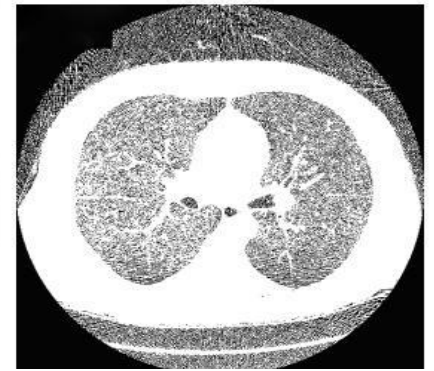

(b) enhanced image
Figure 2.4. Output image after applying FFT techniques

\section{Segmentation of CT scan}

Segmentation of Image is a fundamental advance in mechanized picture investigation and it bargains with isolating classes in an image into consistent and separate districts. For instance, a CT cut from a thoracic output may contain chest segmentation, heart sections, notwithstanding lung tissues. The objective of Segmentation right now to confine the lung tissue. [12-17]

Segmentation of the image is amazingly rich in image analysis and computer vision literature. However, extensively, Segmentation of images on strategies might be ordered into three transparent methodologies, a) measurable, b) geometric, and c) variational.

Measurable strategies model the picture data and cast the area process as mapping. Geometric approaches misuse object shape portrayals so as to isolate the image substance into classes. Variational techniques make an understood portrayal of class limits as far as a bend/surface that advances and cuts the specific item at its limit.

Vol. 4 (5), November 2020, www.ijirase.com
Variational approaches utilize specific models and express models. As far as sectioning the CT filters, we depict a methodology that demonstrates the power data in the CT cuts using the straight model.

In this examination, the utilization of marked based watershed Image Segmentation draws near:

\section{Marker-based Watershed Approach: [22 -27]}

Stage 1: load in the Color Image and Convert it into a Grayscale image.

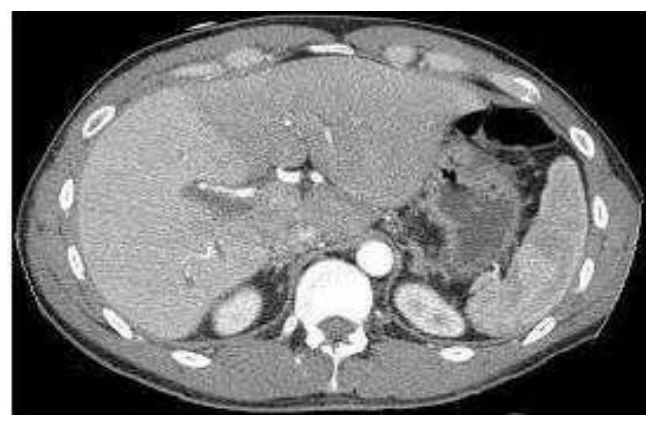

Figure A-1. The original liver CT image

Stage 2: Use of Gradient Magnitude

The Sobel edge veils, filter, and some basic math were utilized to process the inclination greatness. The inclination is high at the fringes of the object and low (for the most part) inside the object.

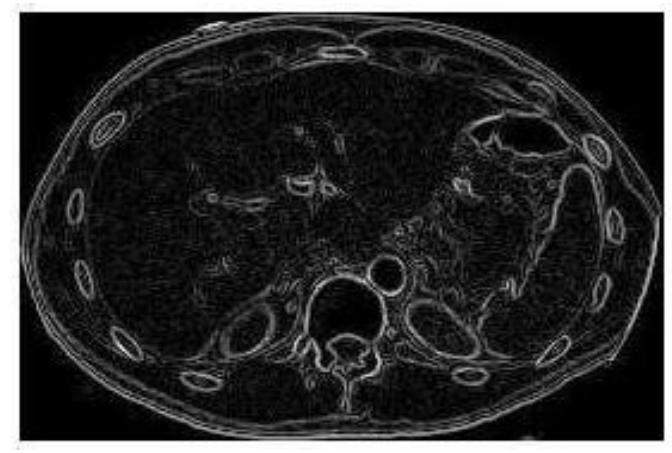

Figure A-2. Gradient Magnitude Function

\section{Stage 3: Marking of Foreground object}

An assortment of systems is applied here to discover the frontal area marking, which is associated with masses of pixels inside every one of the closer view objects. 
- Right now, procedures were utilized and said as "opening-by-reconstruction" and "closing byreconstruction " to "clean up" the picture. These activities will make the level maximum inside each article that can be found.

- Opening is a disintegration followed by an enlargement, while opening-by-reconstruction is a disintegration followed by a morphological remaking. Next, the openingby- reconstruction was figured. [22 -27]

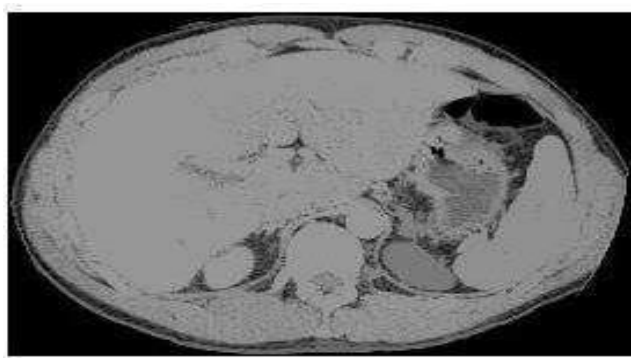

Figure A-3. Opening- by - reconstruction

- Following the opening with an end can evacuate the dim spots and stem marks. Contrast an ordinary morphological shutting and an end by- reconstruction.

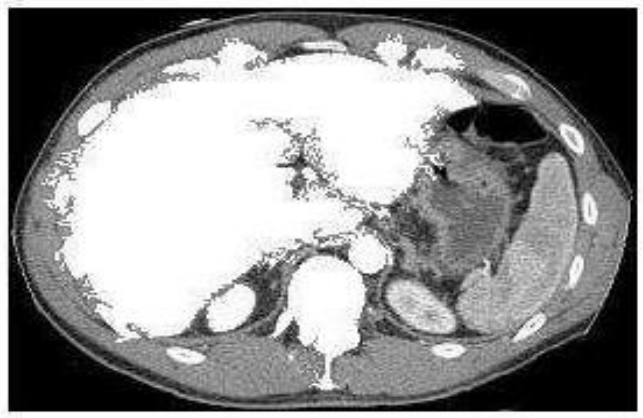

Figure A.4 Regional maxima superimposed technique

- Reproduction based opening and shutting found more convincing than standard opening and closing at ousting little defects without affecting the articles' general conditions. Process the common maxima to get incredible cutting-edge markers.

- A segment of the most hindered and shadowed things is not stepped, which suggests that these articles won't be divided properly finally result. Moreover, the front-line markers in specific things go straight up to the articles' edge. The edges of the marker masses should consummate and subsequently contract them a piece.

Step 4: Marking of Background object [22 -27]

Presently the foundation should be checked. In the cleaned-up image, the dim pixels have a place with the foundation, a thresholding activity could begin with.

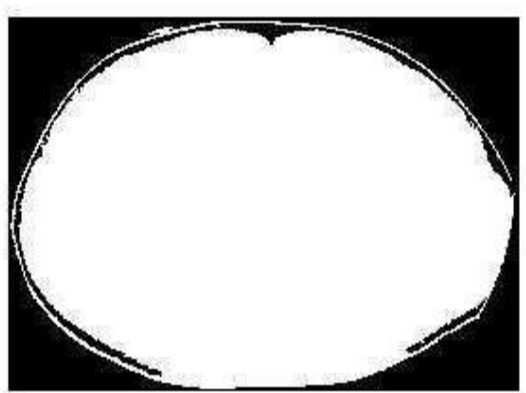

Figure A.5. Threshold opening-by-reconstruction and closing-by-reconstruction

The foundation pixels are in the dark; however, preferably, the foundation markers shouldn't be excessively near the edges of the items which would section. The foundation would "slender" by processing the "skeleton by impact zones", of the frontal area. This should be possible by processing the watershed change of the separation change and afterward searching for the outcome's watershed edge lines.

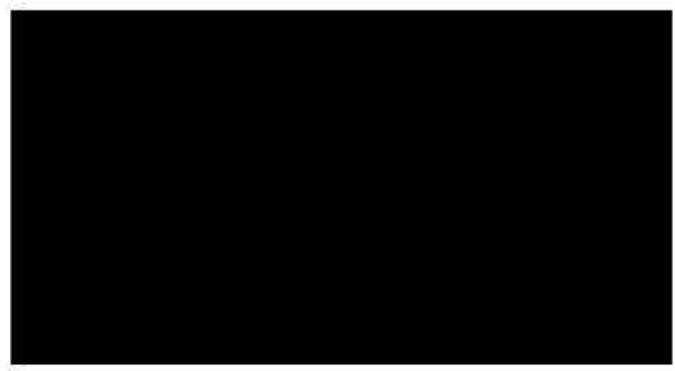

Figure A.6. Watershed ridges of the lines

Step 5: Compute the Watershed based Segmentation. [22 -27]

- The function is utilized to adjust a picture with the goal that it has territorial minima just in certain ideal areas. it is used to change the angle greatness picture to ensure its 
solitary provincial minima happens at closer view and foundation marker pixels.

- At long last the watershed-based Segmentation ready to figure.

Step 6: Visualization of the outcome.

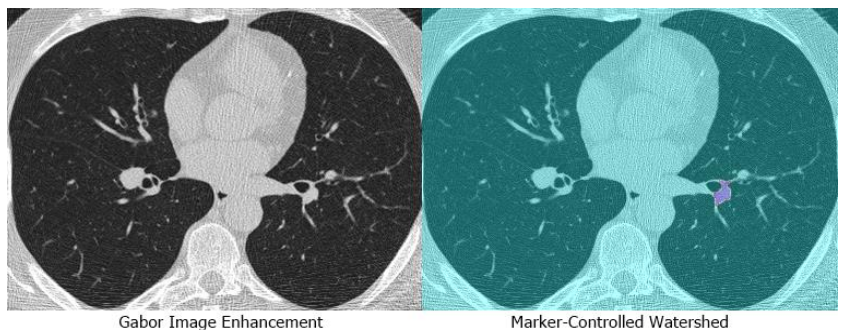

Figure A.7. Segmented image after applying Marker-based Watershed

\section{Extraction of CT Scan}

Change the segmentation function to contain the minima in the foreground marker and background marker position [22 - 27]. When the segmentation process is done on the lung CT scan image, the highlights and the finding rule can be intended to precisely recognize lung infection [1217, 19-21] region knobs. These analytic guidelines may take out the identification of infection knobs bringing about division and give a superior finding.

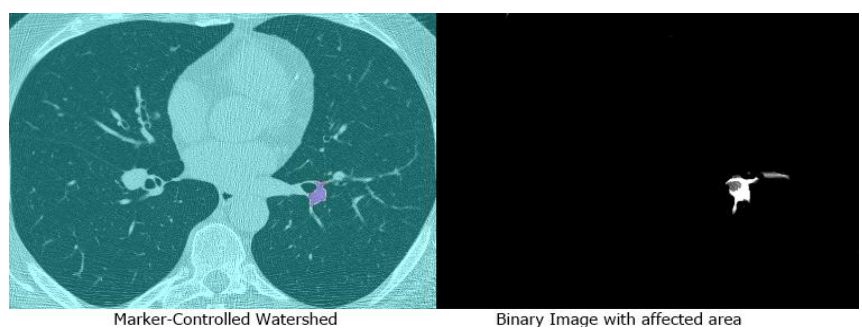

Figure 2.5. Extraction process after applying Segmentation

After Segmentation process on CT scan image, made a dark scale image that pushed us to unique the anomalous knob segments with white shading. At that point it is estimated the areas with following advances. Rough highlights for the discrete knob of given an example were found as follows:

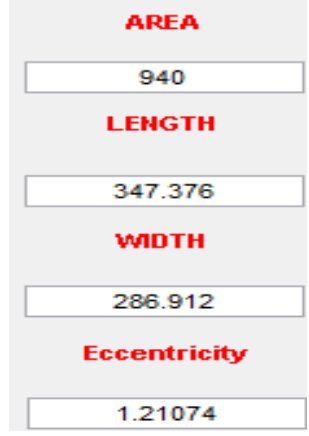

Figure 2.6 Feature Extraction after Segmentation

The proposed strategy has been handled through its preparation steps. Lastly, it ready to distinguish whether the accompanying lung CT scan image is influenced [12-17, 19-21] or not. Diagnosing the essential ailment will improve the patient's endurance rate. The separation between contaminated Pneumonia and non-Pneumonia applicant's knobs which are shown in Figure 2.7 (a), (b) and (c) for making a decision

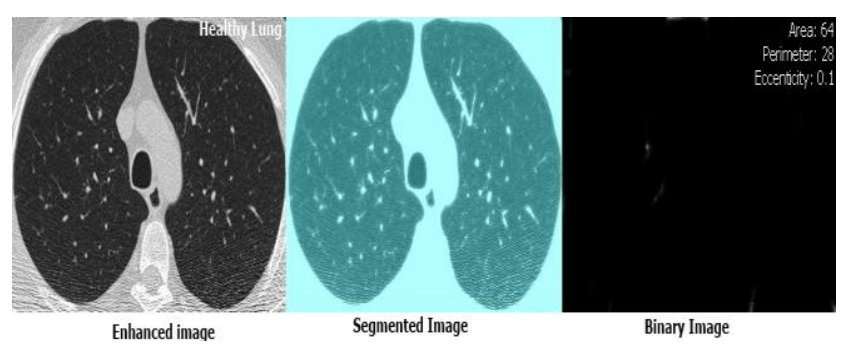

(a) A healthy lung

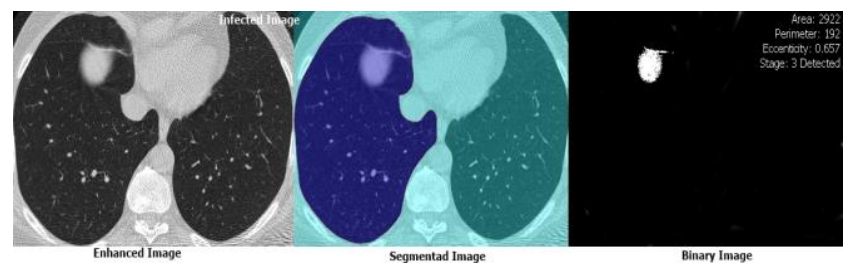

(b) Initial Infection of Pneumonia 


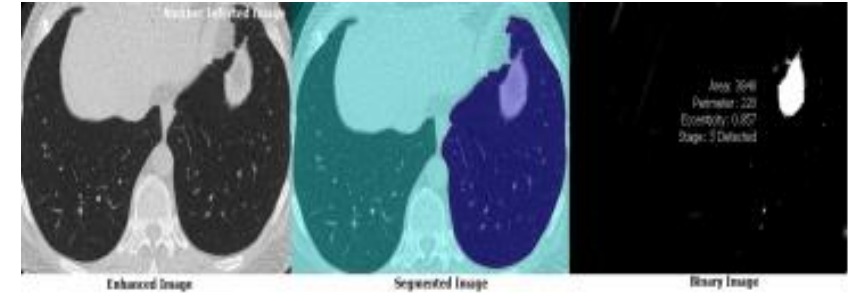

(c) Increased infection of Pneumonia

Figure 2.7 Feature Extraction after Segmentation

\section{EVALUATION PLATFORM}

The watershed strategy is a work of art, a computationally straightforward system for object segmentation in images. The first grayscale picture can be viewed as a topographic alleviation, with brilliance/force compared to elevation. In this manner, distinct watershed lines give a strategy to sectioning an image into isolated spatial regions. The first grayscale image is changed into a 'height map', which accentuates discontinuities in image intensity and dampens continuous regions. The markerbased watershed change enlarges, or floods, from markers that are given to the calculation. The quantity of markers decides the number of areas that will be made by the watershed transform.

Infervision's deep learning clinical imaging stage is helping screen patients for the coronavirus in China. It goes about as a second pair of eyes to recognize different sicknesses from one lot of chest examines. Artificial Intelligence (AI) can give a total perspective on the knob, including volume and thickness.

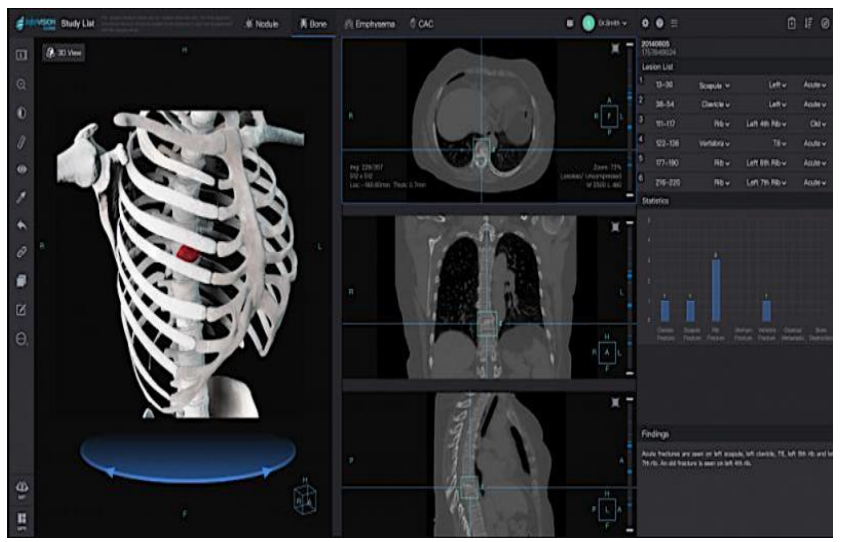

Vol. 4 (5), November 2020, www.ijirase.com

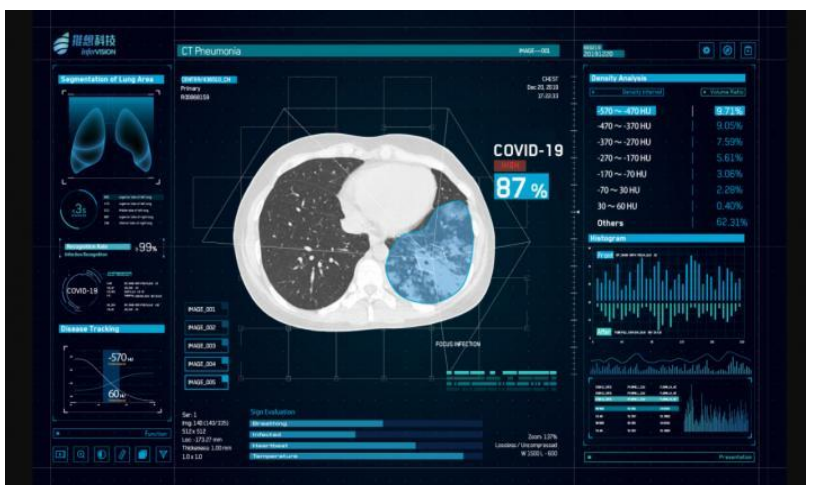

February 29, 2020 - New social insurance innovations are being executed in the battle against the Novel Coronavirus (2019-nCov) flare-up in China. This new tech incorporates human-made consciousness, investigation programming, and utilizing automatons to make conveyances to clinics, as per the medicinal services statistical surveying firm Global Data.

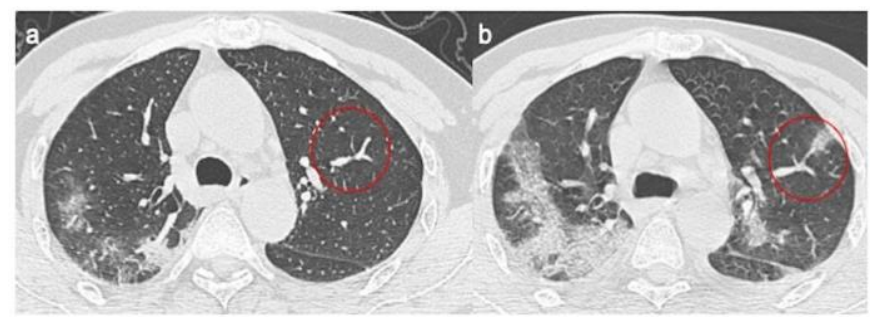

Figure 3.1 (a) Baseline chest CT shows cylindrical size increment of the segmental vessel with typically ventilated nearby lung parenchyma, (b) where following 3 days there is a ground-glass opacities.

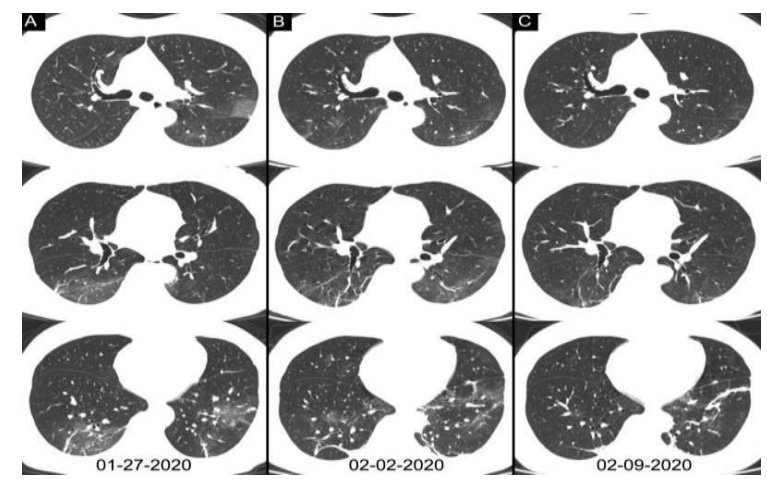

Figure 3.2: CT scan image of a 46-year-elderly person with fever for 4 days. The after effect of RT-PCR nCoV positive on February 4, 2020 and was negative on February 122020. 
The chest CT examines acquired from January 27 (segment A), February 2 (section C) and February 092020 (segment $\mathrm{C}$ ) show the continuous ingestion of reciprocal growth opacities and straight solidification.

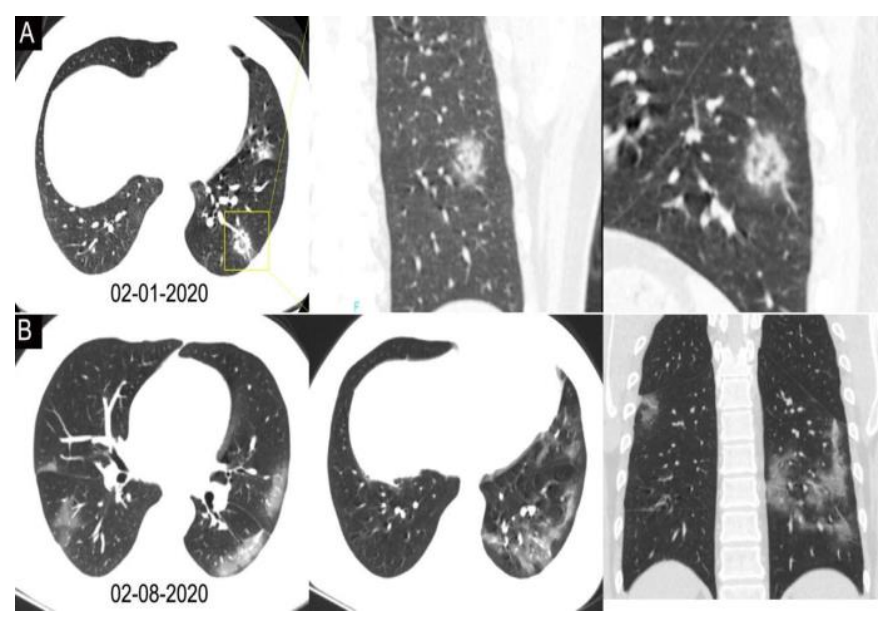

Figure 3.3: CT scan image of a 34-year person with fever for 4 days. The positive result of $\mathrm{nCoV}$ on February 8, 2020.

\section{CONCLUSION}

Right now, contextual investigation, a novel technique has been introduced that could screen 2019-nCov completely naturally by Digital image processing. Models with area consideration system could all the more precisely characterize 2019-nCov at chest radiography with the general exactness and could be a promising valuable symptomatic technique for clinical specialists.

This study proposes and approves a programmed approach for detecting 2019-nCov utilizing marker-based watershed segmentation. CT scan Segmentation of the proposed computerized strategy is evaluated by contrasting results and a very much acknowledged intuitive division technique.

\section{REFERENCES}

[1] https://www.dicardiology.com/article/emerging-technologiesproving-value-chinese-coronavirus-fight

[2] https://www.itnonline.com/content/infervision-frontlinesagainst-coronavirus (Artificial Intelligence | February 04, 2020)

[3] "CT Imaging Features of 2019 Novel Coronavirus (2019nCoV)," Michael Chung, M.D., Adam Bernheim, M.D., Xueyan Mei, M.S., Ning Zhang, M.D., Mingqian Huang, M.D., Xianjian Zeng, M.D., Jiufa Cui, M.D., Wenjian Xu,

Vol. 4 (5), November 2020, www.ijirase.com
M.D., Yang, Ph.D., Zahi Fayad, Ph.D., Adam Jacobi, M.D., Kunwei Li, M.D., Shaolin Li, M.D., Hong Shan, M.D.

[4] Radiologyis edited by David A. Bluemke, M.D., Ph.D., University of Wisconsin School of Medicine and Public Health, Madison, Wis., and owned and published by the Radiological Society of North America, Inc. (https://pubs.rsna.org/journal/radiology)

[5] https://pubs.rsna.org/doi/pdf/10.1148/radiol.2020200230

[6] Novel Coronavirus - China. World Health Organization. https://www. who.int/csr/don/12-january-2020-novelcoronavirus-china/en/. Published January 12, 2020.

[7] Novel Coronavirus (2019-nCoV). World Health Organization. https://www. who.int/emergencies/diseases/novel-Coronavirus-2019. Published January 7, 2020.

[8] Summary of probable SARS cases with onset of illness from November 12002 to July 31 2003. World Health Organization. $\quad$ https://www.who.int/ csr/sars/country/table2004_04_21/en/. Published April 21, 2004.

[9] Middle East respiratory syndrome Coronavirus (MERS$\mathrm{CoV}$ ). World Health Organization. https://www.who.int/emergencies/mers-cov/en/.

[10] Situation report - 8. World Health Organization. https://www.who.int/docs/ defaultsource/Coronaviruse/situation-reports/20200128-sitrep-8ncovcleared.pdf?sfvrsn=8b671ce5_2. Published January 28, 2020.

[11] Huang C, Wang Y, Li X, et al. Clinical features of patients infected with 2019 novel coronavirus in Wuhan, China. Lancet 2020 January 24 [Epub ahead of print].

[12] Hansell DM, Bankier AA, MacMahon H, McLoud TC, Müller NL, Remy J. Fleischner Society: glossary of terms for thoracic imaging. Radiology 2008;246(3):697-722.

[13] Koo HJ, Lim S, Choe J, Choi SH, Sung H, Do KH. Radiographic and CT Features of Viral Pneumonia. RadioGraphics 2018;38(3):719-739.

[14] Ooi GC, Khong PL, Müller NL, et al. Severe acute respiratory syndrome: temporal lung changes at thin-section CT in 30 patients. Radiology 2004;230(3):836-844.

[15] Wong KT, Antonio GE, Hui DS, et al. Severe acute respiratory syndrome: radiographic appearances and pattern of progression in 138 patients. Radiology 2003;228(2):401406.

[16] Ajlan AM, Ahyad RA, Jamjoom LG, Alharthy A, Madani TA. Middle East respiratory syndrome coronavirus (MERSCoV) infection: chest CT findings. AJR Am J Roentgenol 2014;203(4):782-787.

[17] Choi WJ, Lee KN, Kang EJ, Lee H. Middle East respiratory syndrome Coronavirus infection: a case report of serial computed tomographic findings in a young male patient. Korean J Radiol 2016;17(1):166-170.

[18] About 2019 Novel Coronavirus (2019-nCoV). Centers for Disease Control and Prevention. https://www.cdc.gov/Coronavirus/2019ncov/about/symptoms.html. Updated January 31, 2020.

[19] Paul NS, Roberts H, Butany J, et al. Radiologic pattern of disease in patients with severe acute respiratory syndrome: the Toronto experience. RadioGraphics 2004;24(2):553-563.

[20] Yatabe M, Garib D, Faco R, de Clerck H, Souki B, Janson $\mathrm{G}$, et al. Mandibular and glenoid fossa changes after boneanchored maxillary protraction therapy in patients with 
UCLP: A 3-D preliminary assessment. Angle Orthod 2017; 87: 423-31. doi: https://doi.org/10.2319/052516-419.1

[21] Cevidanes LHS, Alhadidi A, Paniagua B, Styner M, Ludlow $\mathrm{J}$, Mol A, et al. Three-dimensional quantification of mandibular asymmetry through cone-beam computerized tomography. Oral Surg Oral Med Oral Pathol Oral Radiol Endod 2011; 111: 757-70. doi: https://doi.org/10.1016/j.tripleo.2011.02.002

[22] Beare R, Chen J, Adamson CL, Silk T, Thompson DK, Yang JYM, et al. Brain extraction using the watershed transform from markers. Front Neuroinform 2013; 7: 1063-74. doi: https://doi.org/10.3389/fninf.2013.00032

[23] Beare R. A locally constrained watershed transform. IEEE Trans Pattern Anal Mach Intell 2006; 28: 1063-74. doi: https://doi.org/10.1109/TPAMI.2006.132

[24] Hai Gao, Ping Xue, Weisi Lin. A new marker-based watershed algorithm. In: Proceedings of the IEEE International Symposium on Circuits and Systems IEEE; $2004 . \quad$ p. 81-4. doi: https://doi.org/10.1109/ISCAS.2004.1329213

[25] Gómez W, Leija L, Alvarenga A V, Infantosi AFC, Pereira WCA. Computerized lesion segmentation of breast ultrasound based on marker-controlled watershed transformation. Med Phys 2010; 37: 82-95. doi: https://doi.org/10.1118/1.3265959

[26] Yan J, Zhao B, Wang L, Zelenetz A, Schwartz LH. Markercontrolled watershed for lymphoma segmentation in sequential CT images. Med Phys 2006; 33: 2452-60. doi: https://doi.org/10.1118/1.2207133.

[27] Yi Fan, Richard Beare, Harold Matthews, Paul Schneider et al. "Marker-based watershed transform method for fully automatic mandibular segmentation from CBCT images", Dentomaxillo facial Radiology, 2018. 